\title{
The Study on Determinants of Consumer Continued Usage Intention of Web TV
}

\author{
YU LIU \\ Finance and Economic School, XI ZANG MIN ZU University, China \\ XIAN YANG City, 710082, China \\ Email:191017804@qq.com
}

Keywords: Web TV, Determinants, Consumer Continued Usage Intention.

\begin{abstract}
This paper analyzes Web TV market condition. Based on this, it identifies the factors which influence the continued usage intention of Web TV. Finally, Provide recommendations for media companies and point out further research directions.
\end{abstract}

\section{Introduction}

Throughout the world, WebTV usage has soared over the past three years. In the US, the number of videos streamed over the web to the PC has increased by $66 \%$ in 2007 , reaching more than 10 billion videos viewed in January 2008, according to com Score video metrics. Similarly, all European countries have experienced double to triple digit growth rates. At the beginning of 2008, the UK is leading European WebTV consumption with more than 3 billion videos viewed per month. Germany and France are rapidly catching up with 2,5 and 2,1 billion, respectively. In line with these figures, Nielsen estimates the average video viewer to spend more than two hours watching WebTV per month. The growth in WebTV consumption, in turn, is driven by both rising user numbers and increased user activity. In Germany for instance, com Score reported $70 \%$ of the online population to be video streaming at least once a month by April 2007. Nine months later, at the beginning of 2008 , WebTV reaches more than $80 \%$ of online users. In addition, the number of monthly videos viewed per video streamer has risen by almost $50 \%$. By now, it clearly exceeds 90 videos viewed - German WebTV users are watching more than three videos per day.

Not surprisingly, media companies all along the value chain are trying to stake their claims of the growing market and move into WebTV on their own. Consequentially, the WebTV boom is fueled both on the supply and demand side. "Increases in broadband penetration have significantly enlarged the targetable WebTV audience", states Alexander Mogg, broadband and media expert at Roland Berger Strategy Consultants. "While at the same time, WebTV players have consistently grown in numbers and improved their offerings through better contents and usability. This, in turn, attracts new users and raises overall WebTV activity in the net", so Mogg. Consequently, it is necessary to research the factors which influence consumers continued usage intention of Web TV.

Based on above, the purpose of this paper is stated: Firstly, survey the current situation of Web TV. Secondly, identify the factors which influence the continued usage intention of Web TV. Finally, Provide recommendations for media companies and Point out further research directions.

\section{Analyses on Web TV Market}

\subsection{Overview of Web TV}

As broadband capacity continues to increase, real- time television programs and video on 
demand, also called webcasting, is made available on the web. According to Chan-Olmsted and Park (2000), webcasting and video-streaming was revealed to be included on broadcast company's websites as early as in 1998. Their research from 2000 showed that 8.3 percent of TV stations web sites contained video-streaming while 15.3 percent offered online audio. This means that traditional television and elements of interactive television (as described above) is made available online through the computer. In this paper we will use the term webTV to point to the fact that we are focusing on television viewed on a computer over the web.

Today, WebTV is accounting for more than $10 \%$ of all internet traffic, according to Cisco estimates. As such, it is the third most important source of online traffic, exceeded only by email/file transfer and peer-to-peer downloading. Clearly, WebTV has developed into a mass application that can build on its own stars, culture and user base. Lonelygirl15 telling her worries ( $>$ 70 million views) or fun two playing Pachelbel's Canon on his electric guitar ( $>44$ million views) are only two of the manifold examples that have found their way into the hearts of a rapidly growing WebTV audience.

\subsection{The Difference between Web-TV, IPTV and Traditional TV}

Technologically, one can first distinguish Web- and IPTV from "traditional TV". Both Weband IPTV are transmitted via a bidirectional IP infrastructure, whereas "traditional TV" is broadcasted terrestrially, via satellite or cable. However,

WebTV still clearly differs from IPTV in such that WebTV providers do not guarantee a picture quality that is equal to or better than "traditional TV". WebTV is offered by independent providers "over the top" of the Telco's network, whereas IPTV products are provided by walled garden infrastructures, using the proprietary end-to-end platform of the operator. Hence, WebTV is a "best effort" model in which the provider can hardly influence the quality of service (QoS) over the public Internet - a drawback. Nevertheless - for now -WebTV is mainly targeted at PC screen usage, whereas IPTV is usually consumed on the TV screen.

In terms of content, there is still a lot of discussion about which online services shall be subsumed under the term WebTV. Differentiations are being made between user generated vs. commercial contents; VoD vs. linear channels; free vs. pay; player- vs. client-based; short vs. long duration clips, etc. We, however, broadly classify any IP-based moving picture service, that is not an insulated IPTV model, under the term WebTV. "Convergence is also taking place between formerly distinct online video or TV services", states Alexander Mogg. "We can observe all-embracing WebTV offerings like Telefonica's Terra TV, which comprise the whole range of online moving picture services under one brand. Many of the established players are expanding product lines and services or reinvent themselves as full-line providers".

Furthermore, for consumers, WebTV in the first place means open access to the world of digital, IP-based television via a standard internet connection. "WebTV has opened the advantages of next generation TV services to the whole internet population. Enlarged content libraries, on demand accessibility and time-shift functions are only some of the features that together comprise WebTV's value proposition to all internet users", says Alexander Mogg. "As a consequence, large online communities have grown around the basic content offerings. 


\section{Technology Acceptance Model (TAM) for Web TV}

\subsection{Technology Acceptance Model (TAM)}

The Technology Acceptance Model (Davis 1989; Davis, Bagozzi and Warshaw1989) is one of the most frequently utilized end-user technological adoption frameworks. The goal of TAM is "to provide an explanation of the determinants of computer acceptance that is general, capable of explaining user behavior across a broad range of end-user computing technologies and user populations, while at the same time being both parsimonious and theoretically justified". The TAM represents an important theoretical contribution toward understanding Technology usage and technology acceptance behaviors. The viability of TAM has been successfully tested in various technology acceptance studies in different areas, including the Internet, World Wide Web, and electronic commerce. Some researchers studied the factors influencing T-commerce by users, showed that the perceived enjoyment is most important factor affecting usage of T-commerce. Recently more TAM has been enhanced to include a hedonic component of enjoyment but the effect has rarely been investigated in a mobile commerce. During this research, two factors have been found, which are perceived usefulness and perceived ease, all of which ultimately influenced consumers' continued intentions towards the Web-TV.

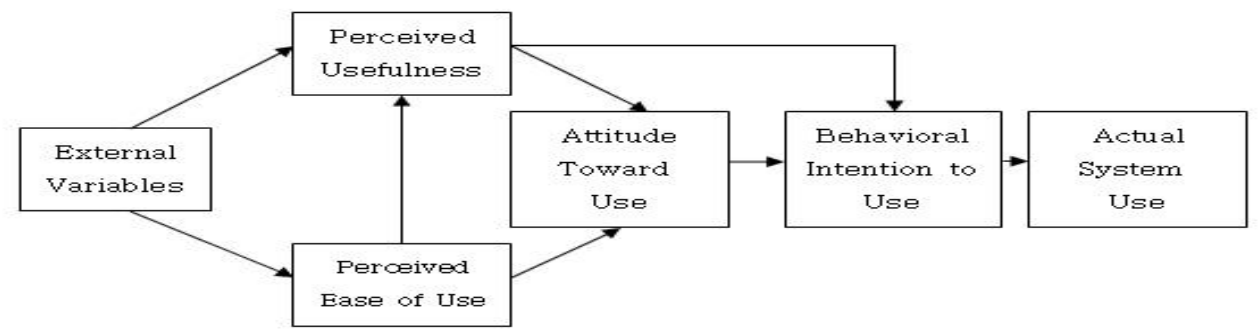

Fig. 1 Technology Acceptance Model

\subsection{Technology Acceptance Model (TAM) for Web TV}

The further process of carrying on this research is to build the model. Although some previous studies have identified some factors would influence the continued usage of customers in the Web business, the model in this study was built that included the effect of the consumer's perceived usefulness and ease in Web TV. If the Web TV, as a new technology, lost these factors, it would lose the consumer and markets. In the model, there are four related factors: Interactivity, Split Screen, Personalization, Global Connectivity. Because of they could affect the consumers' decision of choosing mobile-TV, choose the four aspects as main variable.

At the aspect of the model, the TAM model was chosen as the foundation of our research model. The perceived usefulness and flow are the medium variable in our research model. Consumer satisfaction and continued usage intention are the final variables. The research model is indicated in figue-6: 


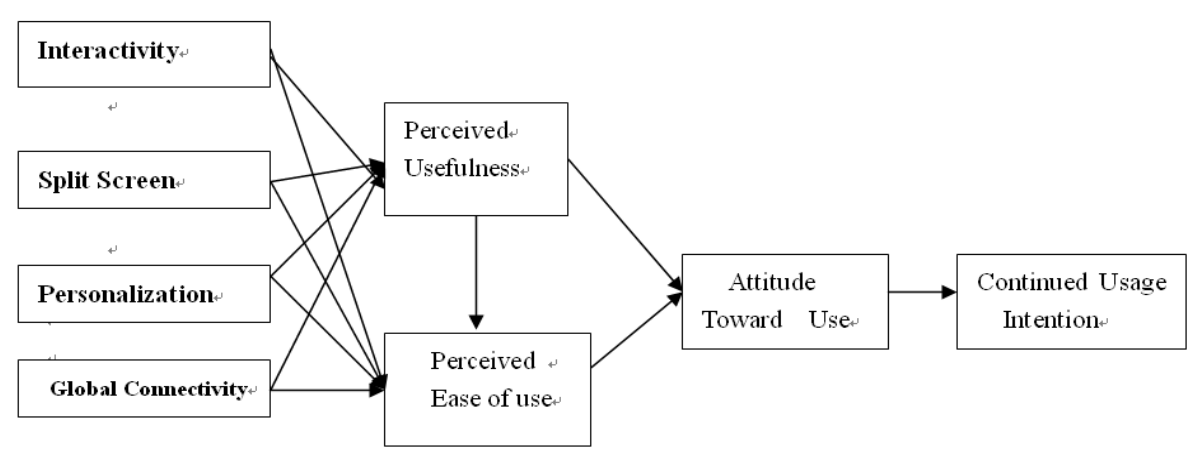

Fig. 2 Research Model

\subsubsection{Interactivity}

Interactivity opens up new opportunities for broadcast companies. Hoffman and Novak (1996) draw a line between person- interactivity (communication through a medium) and machine interactivity (interactively access to hypermedia content). Person-interactivity is defined by Blattberg and Deighton (1991) as a facility that makes it possible for individuals and organizations to communicate regardless of distance and time. WebTV can take advantage of person-interactivity for example by the implementation of services that makes it possible for viewers to make comments or ask questions to people taking part in a TV show. Moreover, chat rooms or message boards can be offered on web TV (Ha, 2002), making it possible for the broadcast company's customers to express their opinions about programs on the web TV and to discuss programs and/or related issues both with other viewers and with representatives of the brand/TV-channel. Machine- interactivity, on the other hand, is defined by Steuer (1992, p. 84) as "the extent to which users can participate in modifying the form and content of a mediated environment in real time". Thus, interactivity is defined as a situation where television is not a one-way distribution channel through which the broadcast company pushes programs to the consumer. Rather, interactivity implies that the consumer can take an active part in deciding what to watch and when to watch television. This benefit means that web TV makes it possible for the individual customer to watch programs at the time and location that suits them best.

\subsubsection{Split screen}

Another possibility enabled by web TV is to split the computer screen into two or more windows, making it possible to watch more than one program at the same time (Pra mataris et. al., 2001). For example, it will be possible to view a movie in one of the screens in a low involvement modus while at the same time browsing through the latest news in another screen. According to Balasu bramanian, Peterson, and Jarvenpaa (2002), time is a resource that is very limited in a modern persons' life. Thus, the split screen function may be an effective way of accessing information and entertainment for customers with a busy everyday life schedule.

\subsubsection{Personalization}

Personalization is defined as the possibility to adjust information and content to each customers unique needs and preferences (Roehm \& Haugtvedt, 1999; Bezjian-Avery, Calder, \& Icabucci, 1998). Often, such adjustments are based on user profiles and identification. According to Dransfield et al. (1999), television on the web enables a personalized approach with the targeting of viewer groups and individuals. The personalization characteristic follows as a result of the interactivity dimension. Personalized websites are simply dynamic websites where each consumer 
can get personally tailored information and services based on her/his personal user profile. As on the web, interactivity increase broadcast companies' competitive advantage because personalized and relevant information to the TV viewers are enabled (Pramataris et al., 2001). Personalization entails that the individual customer - based on his/her preferences - can get tailor made broadcast services, get access to support services that are adapted to their personal profile, and that he/she also has the possibility to subscribe to services that is in accordance to the individuals' profile.

\subsubsection{Global connectivity}

While some of the largest television broadcast companies have been accessible through cable and satellite television for several years, smaller niche broadcast companies has traditionally been ring-fenced with national boundaries (Jacobs \& Dransfield, 1998). Various digital television solutions have been introduced by media companies, and incompatible set-top boxes have been used in various countries, thus limiting the global access to many broadcast companies. On the Internet, however, problems with incompatibility are almost non-existing. It usually makes no difference whether a customer access the web-TV site using a PC, an Apple Macintosh o r some other platform (Jacob \& Dransfield, 1998), thus making global broadcasting available also for smaller niche broadcast companies.

\section{Technology-centered Customer Satisfaction Strategy for Web TV}

4.1 Professionalization - Contract structures between content owners and WebTV players are becoming increasingly professionalized and standardized. Advertising-funded revenue sharing on country level is developing as the prevalent business model. Minimum guarantees are typically incorporated in contracts involving premium content from producers with strong brands, ensuring a sufficient return on their investments. With thus facilitated enlarged and premium-oriented content offerings, new usage patterns are evolving. The recent entries of the majors into WebTV might hence also be seen as first indicators for an upcoming increase in short tail consumption over the web.

4.2 Mobilization - Mobile networks are experiencing significant increases in bandwidth capacity and the equipment of handsets with TV-capable screens is soaring. WebTV players respond to the rapidly upcoming mobile content usage through the implementation of mobile compatible microsites, new video formats (3gp) and mobile software clients. In parallel, mobile carriers are lowering data tariffs and try to monetize on the increasing mobile broadband usage through the creation of own, dedicated mobile content offerings. As a consequence, mobile video usage is taking off and the global user base is forecast to continue to grow with CAGRs up to $100 \%$ over the next five years, reaching almost one billion people in 2012.

4.3 Convergence - WebTV is starting to become an integral part of the living room entertainment sphere. Integrative devices like Linksys' Kiss 1600 or United Internet's

Media Center enable users to comfortably access navigate and stream WebTV contents on their home televisions. In parallel, established players like Apple are creating their own devices as TV-extensions for their contents (Apple TV). In that way, WebTV begins to move away from a separated web application to a real alternative to traditional TV - thereby constituting new competition on share of time and share of wallet for traditional broadcasters. However, many steps remain to be taken before entering the mindset of living room occupants accustomed to traditional TV. 


\section{Future outlook - WebTV will benefit from multi device accessibility and position itself in direct competition to established operators and broadcasters}

The future development of WebTV offerings will be highly influenced by multi device accessibility and multi screen consumption patterns. Laptop/PC, Mobile and TV screen will become similar in importance but have different implications on the design of WebTV offerings. "Established WebTV players will try to leverage their existing contents and infrastructures to harvest market share in mobile video and TV consumption - Either through adaptation of their existing clients, web pages and contents or through the creation of new, parallel offerings." expects Alexander Mogg. "At the same time, new players will enter the field with specialized content or webpage/client offerings for Mobile or TV screens.

\section{Acknowledgements}

In this paper, the research was sponsored by the Major Project Cultivation Program of XI ZANG MIN ZU University (Project No. 17MDZP01).

\section{References}

[1] Bruner, G. and Kumar, A.,"Explaining consumer acceptance of handheld Internet devices", Journal of Business Research 58, 2003, pp. 115-120.

[2] Caruso, P. E., "Multimedia ON MOBILE TVV CONTENT PREPARATION AND OPTIMIZATION", CBC TECHNOLOGY REVIEW, Issue 3 - January 2007.

[3] Chellappa, R. and Pavlou, P., "Perceived information security, financial liability and consumer trust in electronic commerce transactions", Logistics Information ManagementVolume 15 Number 5, 2002 pp. 358-368.

[4] Childers, T., Carr, C., and Peck, J., "Hedonic and utilitarian motivations for online retail shopping behavior", Journal of Retailing 77, 2001, pp. 511-535.

[5] Cui, Y.Q., Jan C., and Jung, Y., "Personal TV: A Qualitative Study of Mobile TV Users", Report of Nokia Research Center Helsinki, 2005.

[6] Cyr, D, Bonanni, C. and Ilsever, J., "Design and E-loyalty across cultures in electronic commerce", in: Proceedings for the Sixth International Conference on Electronic Commerce (ICEC04), published by the Association for Computing Machinery (ACM), 2004.

[7] Dam, R.V.D., "Primetime for Mobile Television-Extending the entertainment concept by bringing together the best of both worlds", IBM Global Business Service, 2006.

[8] Davis, F.D., "Perceived usefulness, perceived ease of use, and user acceptance of information technology". MIS Quarterly, 1989, 319-340.

[9] DeLone, W.H. and McLean, E.R. "Information Systems Success: The Quest for the Dependent Variable," Information Systems Research, 1992.

[10] Dishaw, M. T. and Strong, D. M., "Extending the technology acceptance model with task-technology fit constructs”. Information \& Management, 1999, 36(1), 9-21.

[11] Kaasinen, E., "User acceptance of mobile services-value, ease of use, trust and ease of adoption”, VTT Technical Research Centre of Finland, 2005.

[12] Kang, S.C., "A Research on Factors Influencing Applications of Mobile Contents”,Department of Management Information Systems Graduate School of Business Administration, Cheju National University, 2006.

[13] Kivisaari, E., and Luukkainen, S., "Markets and Strategies for Mobile Broadcast in Finland, Helsinki University of Technology", Telecommunications Software and Multimedia Laboratory, 2005. 
[14] Koufaris, M., "Applying the technology acceptance model and flow theory to online consumer behavior”, Information Systems Research 13 (2), 2002, pp. 205-223.

[15] Lee, S.W. and Kwak, D. K., TV in your cell phone: the introduction of Digital Multimedia Broadcasting (DMB) in Korea, paper presented at the 33rdTelecommunications Policy Research Conference (TPRC), Arlington, VA, September 23-25, 2005.

[16] Nagash, S., Ryan, T. and Igbaria, M., "Quality and effectiveness in web-based customer support system," Information \& Management, 40(8), 2003, pp.757-768.

[17] Satu H. J., Ville P. I., Kaisa A. V., "Effect of TV Content in Subjective Assessment of Video Quality on Mobile Devices", Multimedia on Mobile Devices, edited by Reiner Creutzburg, Jarmo H. Takala, Proc. of SPIE-IS\&T Electronic Imaging,Vol.5684,2005.

[18] Sendecka, L., “Adoption of mobile services Moderating effects of service's information intensity”, NORGES HANDELSHØYSKOLE Bergen, spring 2006.

[19] Trefzger, J., "Mobile TV-Launch in Germany -Challenges and Implications", Working Papers of the Institute for Broadcasting Economics Cologne University, No. 209, November, 2005. 